\title{
Processos excludente em uma sociedade em construção
}

Exclusive processes in a society under construction

\author{
Isadora Oliveira Gondim ${ }^{1 *}$, Amanda Menezes Oliveira ${ }^{1}$, Ana Paula de Lima Bezerra ${ }^{1}$, Karla \\ Rona da Silva ${ }^{2}$, Fernanda Gonçalves de Souza ${ }^{1}$
}

\begin{abstract}
RESUMO
A inclusão de pessoas com deficiência (PCD) é um desafio relevante e ainda estamos caminhando para o ideal.Por esse motivo, o objetivo do trabalho é analisar criticamente em qual medida a inclusão é efetiva no contexto e na sociedade atual, considerando a assimetria na prática vivenciada pelos PCD. Em relação à metodologia, foi realizada uma revisão integrativa de literatura nas bases de dados indexadas LILACS, BDENF, Coleciona SUS e na Secretaria Estadual de Saúde de São Paulo, tendo como base a questão norteadora "Quais informações foram publicadas em periódicos indexados, de Janeiro 2015 a Julho de 2020, que permitem analisar criticamente, em que medida a inclusão ainda é excludente?".As observações foram feitas considerando diferentes cenários, sendo assim a inclusão ainda é um aspecto em construção, porém encontram-se na sociedade fatores que impedem a consolidação, sendo alguns enraizados, com repetição de atitudes prejudiciais, de forma marcante. Além disso, é notada a visão diversificada das minorias, dependendo do contexto e aspectos sociais, tornando necessárias abordagens diferentes para mudar essa mentalidade e buscando promover a liberdade da PCD, sempre com autonomia.
\end{abstract}

Palavras-chave: Inclusão; Exclusão; Pessoa com Deficiência;

\begin{abstract}
The inclusion of people with disabilities (PWD) is a relevant challenge and we are still moving towards the ideal.For this reason, the aim of this work is to critically analyze to what extent inclusion is effective in the current context and society, considering the asymmetry in practice experienced by PWD. Regarding the methodology, an integrative literature review was conducted in the indexed databases LILACS, BDENF, Coleciona SUS and the São Paulo State Department of Health, based on the guiding question "What information was published in indexed journals, from January 2015 to July 2020, that allows to critically analyze, to what extent inclusion is still exclusionary? "The observations were made considering different scenarios, thus inclusion is still an aspect under construction, but there are factors in society that prevent the consolidation, some of which are rooted, with repetition of harmful attitudes, markedly. Moreover, it is noted the diverse view of minorities, depending on the context and social aspects, making necessary different approaches to change this mentality and seeking to promote the freedom of the PCD, always with autonomy.
\end{abstract}

Keywords: Inclusion; Exclusion; Person with Disabilities;

\footnotetext{
${ }^{1}$ Discente de Gestão de Serviços de Saúde - Universidade Federal de Minas Gerais.

*E-mail: isadoraoliveira999@gmail.com

${ }^{2}$ Professora Doutora atuando no Mestrado Profissional e na Graduação em Gestão de Serviços de Saúde - Universidade Federal de Minas Gerais
} 


\section{INTRODUÇÃO}

A inclusão envolve a participação ativa dos indivíduos com deficiência no convívio social, promovendo integração ao meio. As Pessoas com Deficiência (PCD) são aquelas que têm impedimento de longo prazo de natureza física, mental, intelectual ou sensorial, que sem transposição das barreiras impedem sua plena e efetiva vivência na sociedade em igualdade de condições com os demais. Para isso, em algumas situações, é necessário garantir a equidade vertical de acesso. Além disso, fatores facilitadores têm grande impacto, colocando em prática o conceito de acessibilidade, que é pautado na eliminação de barreiras que impedem a participação mais eficiente de um indivíduo, seja no meio social, familiar e/ou escolar. Em relação a acessibilidade, seu conceito pode ser dividido nos seguintes aspectos: arquitetônica, relacionada com a eliminação de barreiras físicas, metodológica, envolvendo a adequação dos métodos de ensino, instrumental, que engloba a adequação de materiais que ajudem a eliminar as barreiras e também, atitudinal, que tem coparticipação marcante da comunidade, pois possui o princípio de diminuir o preconceito e comportamentos prejudiciais à inclusão de pessoas com deficiência (CORREA, 2009; KASTRUP; THOMA; SOUSA, 2018).

A constituição de 1988, também chamada de "constituição cidadã", foi um ganho social. Nesse cenário, embasada na luta popular e no processo de redemocratização, representou uma conquista de direitos, gerando ganho para todos os indivíduos, inclusive para as pessoas com deficiência. Entretanto, o estatuto específico da pessoa com Deficiência - Lei n ${ }^{\circ}$ 13.146/2015 foi formalizada apenas em 2015, dando seguimento no processo anteriormente iniciado com o objetivo de "assegurar e promover, em condições de igualdade, o exercício dos direitos e das liberdades fundamentais por pessoa com deficiência, visando a sua inclusão social e cidadania" (BRASIL, 1988; BRASIL, 2015; KASTRUP et al., 2018).

Desta forma, a acessibilidade é uma ferramenta para consolidação da inclusão. Com o propósito de estabelecer um ambiente inclusivo, colocando essas definições na prática, se utilizando da convivência. Na atualidade existe a Lei de cotas, auxiliando na inserção de pessoas com deficiência em diferentes espaços, como no meio universitário e no mercado de trabalho (MANZINI, 2006; FIGUEIREDO et al., 2011). A Lei de cotas é anterior ao estatuto da pessoa com deficiência, representando um marco, no sentido de construção de uma sociedade inclusiva. Sendo assim, a Lei 7.853, de 24 de outubro de 
1989, que declarou apoio às pessoas portadoras de deficiência e sua integração social, assegurando pleno exercício dos direitos sociais nas áreas da educação, saúde, formação profissional e trabalho, teve impacto no surgimento da Lei 8.213, de 24 de julho de 1991, art. 93, chamada de Lei de Cotas, tratando a respeito da proporção de vagas que devem ser destinadas aos portadores de deficiência, isso considerando a quantidade de funcionários, sendo de: $2 \%$ até 200 funcionários, 3\% de 201 a 500 funcionários, $4 \%$ de 501 a 1000 funcionários e 5\% quando há mais de 1001 funcionários na empresa (BRASIL, 1989; BRASIL, 1991).

Apesar de tudo, mesmo com a legislação e o estabelecimento de regras e punições, ainda ocorre uma inclusão excludente. Nessa conjuntura, as pessoas com deficiência estão inseridas na sociedade, mas sem uma integração apropriada, isso tem impacto em uma inclusão física, com a colocação do ser social no contexto, mas pouco efetiva na promoção do diálogo, do respeito e no estabelecimento de laços, para além da autonomia e liberdade desses cidadãos. Dessa forma, apesar do avanço, existem comportamentos persistentes e enraizados na sociedade, esses fatores precisam ser considerados e superados, pois a mobilização social e responsabilização são importantes para o avanço das ações (MACIEL, 2000; MAZZOTA; D'ANTINO, 2011).

Assim, o objetivo deste trabalho foi analisar criticamente, à luz da literatura, em qual medida a inclusão é efetiva no contexto e na sociedade atual, considerando a assimetria na prática vivenciada pelas Pessoas com Deficiência.

\section{METODOLOGIA}

Trata-se de uma uma revisão integrativa de literatura, que consiste em realizar o processo de reunir e sintetizar o conhecimento por meio da análise dos resultados comprovados em pesquisas primárias. $\mathrm{O}$ desenvolvimento desta revisão adota $\mathrm{o}$ referencial teórico proposto por Ganong (2007), considerando as seguintes etapas: a) seleção da pergunta norteadora do estudo; b) amostragem; c) representação das características da pesquisa; d) análise das pesquisas selecionadas; e) análise dos resultados e interpretação para a construção do relatório de revisão (ALMEIDA, 2014; MANCINI; SAMPAIO, 2006).

Desta forma, são colocados parâmetros para direcionar a busca, como intervalo de tempo, idioma e critérios de exclusão, portanto, de forma comparativa e complementar, é possível agregar e enriquecer o que já foi feito, considerando as 
conclusões de outros autores (ALMEIDA, 2014; MANCINI; SAMPAIO, 2006). Com isso, a pergunta norteadora do estudo foi: Quais informações foram publicadas em periódicos indexados, de janeiro 2015 a julho de 2020, sobre o desenvolvimento de ações de inclusão?

Os critérios de inclusão foram: artigos completos publicados em periódicos científicos indexados em bases de dados nacionais e internacionais que abordassem a temática do estudo "inclusão excludente em uma sociedade em construção", nas línguas portuguesa e inglesa, no período de de janeiro 2015 a julho de 2020, nas bases de dados Literatura Latino-americana e do Caribe em Ciências da Saúde (LILACS), Base de Dados de Enfermagem (BDENF), Coleciona SUS e na Secretaria Estadual de Saúde de São Paulo, localizáveis por intermédio dos descritores cadastrados no portal de Descritores das Ciências da Saúde (DeCS): Inclusão; Exclusão Social; e Pessoas com Deficiência.

A estratégia de busca aplicada empregou-se o operador booleano AND para que os descritores "inclusão" e "exclusão social" estivessem entre os descritores. Para os critérios de exclusão utilizados foram: publicações duplicadas, que não respondessem à pergunta norteadora e que não abordassem o tema do estudo. Ao selecionar os estudos incluídos desta revisão, aplicou-se a recomendação Preferred Reporting Items for Systematic Reviews and Meta-Analyses (Prisma), o processo de seleção está representado na Figura 01 (GALVÃO et al., 2015).

Figura 1 - Fluxograma de seleção dos estudos para revisão integrativa de literatura

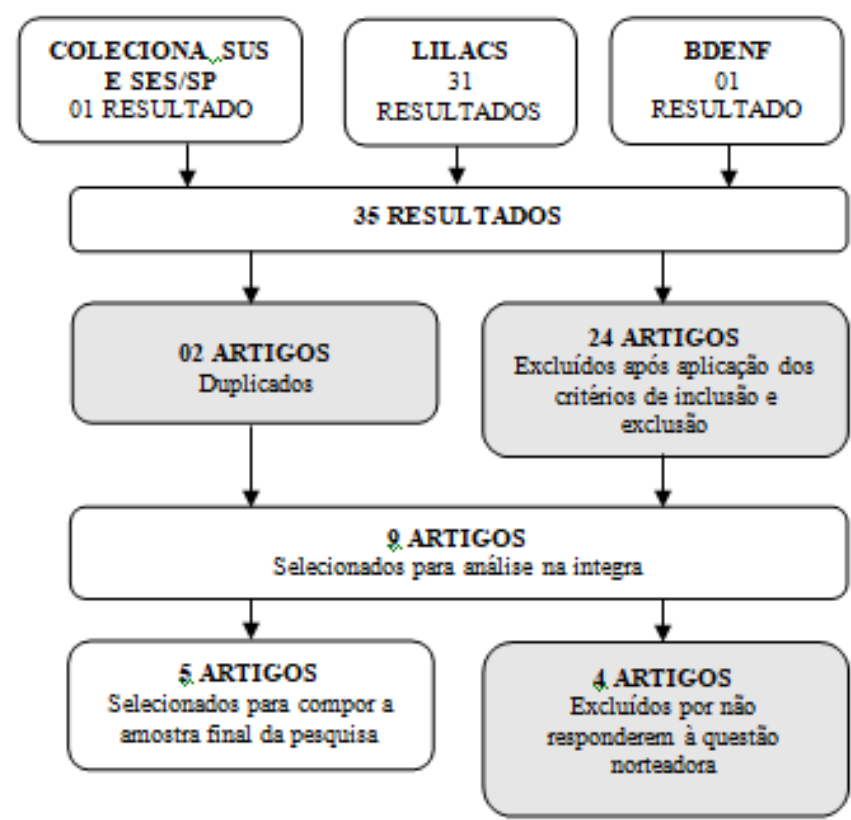

Fonte: Elaborado pelas autoras, 2020. 
Os artigos selecionados foram lidos na íntegra, e empregou-se dois tipos de análises: (1) descritiva, guiada pelo quadro sinóptico construído pelas as autoras contendo informações metodológicas e bibliométricas dos estudos selecionados (título do artigo e ano de publicação, autores, objetivo, delineamento da pesquisa, resultados); e (2) interpretativa, identificando evidências e as analisando a fim de fazer inferências

\section{RESULTADOS}

Foram analisados 5 artigos que atenderam aos critérios de inclusão e exclusão estabelecidos. O Quadro sinóptico (Quadro 1) apresenta a seleção final dos estudos para análise de instrumento de avaliação do estudo.

Quadro 1 - Síntese dos estudos analisados segundo título, país e ano de publicação, autores, objetivo, delineamento e resultados

\begin{tabular}{|c|c|c|c|}
\hline $\begin{array}{c}\text { Título, país, } \\
\text { autor e ano de } \\
\text { publicação }\end{array}$ & Objetivo & Delineamento & Resultados \\
\hline $\begin{array}{lr}\text { A Modulação das } \\
\text { Condutas } & \text { das } \\
\text { Pessoas } & \text { com } \\
\text { Deficiência } & \text { no } \\
\text { Contexto } & \\
\text { Educacional } & \\
\text { Brasileiro } & \text { de } \\
\text { Inclusão. } & \\
& \\
\text { KRAEMER; } & \\
\text { THOMA. } & \\
\text { Brasil, 2019. }\end{array}$ & $\begin{array}{l}\text { Analisar como vêm } \\
\text { sendo } \\
\text { operacionalizados } \\
\text { investimentos na } \\
\text { modulação } \\
\text { condutas das } \\
\text { pessoas das } \\
\text { deficiência pem } \\
\text { política de inclusão } \\
\text { escolar em curso na } \\
\text { sociedade brasileira } \\
\text { desde a última } \\
\text { década do século } \\
\text { XX. }\end{array}$ & $\begin{array}{l}\text { Estudo qualitativo } \\
\text { com a } \\
\text { problematização } \\
\text { dos conceitos de } \\
\text { governamento e } \\
\text { de modulação que } \\
\text { são tomados como } \\
\text { ferramentas } \\
\text { analíticas. }\end{array}$ & $\begin{array}{l}\text { As políticas sociais e } \\
\text { educacionais } \\
\text { operacionalizadas pelo } \\
\text { Estado brasileiro nas últimas } \\
\text { décadas não visam somente à } \\
\text { igualdade, mas ao } \\
\text { estabelecimento de condições } \\
\text { equânimes. As políticas de } \\
\text { inclusão neoliberais exigem } \\
\text { maior mobilidade dos } \\
\text { sujeitos para mantê-los } \\
\text { sempre em atividade e } \\
\text { incluídos, ainda que em } \\
\text { diferentes níveis de } \\
\text { participação. }\end{array}$ \\
\hline $\begin{array}{l}\text { A violência como } \\
\text { tema transversal } \\
\text { aos estudos sobre } \\
\text { a deficiência: } \\
\text { interconexões } \\
\text { necessárias. } \\
\text { WANDERER; } \\
\text { PEDROZA. } \\
\text { Brasil, } 2015 \text {. }\end{array}$ & $\begin{array}{l}\text { Explorar os pontos } \\
\text { de encontro entre os } \\
\text { objetos de estudo } \\
\text { da deficiência e da } \\
\text { violência, } \\
\text { apontando a } \\
\text { necessidade de que } \\
\text { suas interconexões } \\
\text { sejam abordadas } \\
\text { pela psicologia e } \\
\text { áreas afins. }\end{array}$ & $\begin{array}{l}\text { Análise crítica da } \\
\text { literatura. }\end{array}$ & $\begin{array}{l}\text { A partir das análises } \\
\text { empreendidas neste trabalho, } \\
\text { entendemos poder apontar } \\
\text { alguns aspectos que se } \\
\text { referem a possíveis } \\
\text { contribuições que a } \\
\text { psicologia pode oferecer na } \\
\text { construção de políticas } \\
\text { públicas que atuem na } \\
\text { minoração do fenômeno aqui } \\
\text { focalizado. Consideramos }\end{array}$ \\
\hline
\end{tabular}




\begin{tabular}{|c|c|c|c|}
\hline & & & $\begin{array}{l}\text { essencial que a psicologia } \\
\text { contribua para a } \\
\text { desinvisibilização } \\
\text { violência contra pessoas com } \\
\text { deficiência, }\end{array}$ \\
\hline $\begin{array}{l}\text { Autodeterminação } \\
\text { emoções e } \\
\text { exclusão num } \\
\text { blog de pessoas } \\
\text { surdas: um olhar } \\
\text { qualitativo. } \\
\text { ALZUGUREN; } \\
\text { SANCHEZ- } \\
\text { GOMEZ; } \\
\text { COSTA. } \\
\text { Brasil, } 2019 .\end{array}$ & $\begin{array}{l}\text { Explorar as } \\
\text { percepções de bem- } \\
\text { estar que os surdos } \\
\text { colocam em um } \\
\text { blog na Internet. }\end{array}$ & $\begin{array}{l}\text { Metodologia } \\
\text { qualitativa com } \\
\text { análise de } \\
\text { discurso em } \\
\text { língua de sinais de } \\
44 \text { mensagens de } \\
\text { vídeo publicadas } \\
\text { por blogueiros } \\
\text { surdos. }\end{array}$ & $\begin{array}{l}\text { Os participantes do estudo } \\
\text { afirmam que os planos } \\
\text { adotados para sua inclusão } \\
\text { não são suficientes, e eles } \\
\text { sentem desconforto em todas } \\
\text { as áreas e fases da vida. É } \\
\text { preciso eliminar as barreiras } \\
\text { da comunicação e criar } \\
\text { iniciativas de solidariedade } \\
\text { com verdadeiros agentes } \\
\text { transformadores da sociedade } \\
\text { em que vivemos. }\end{array}$ \\
\hline $\begin{array}{l}\text { Apreendendo a } \\
\text { inclusão social } \\
\text { sob o olhar das } \\
\text { representações } \\
\text { sociais }\end{array}$ & $\begin{array}{lr}\text { Investigar } & \text { as } \\
\text { representações } & \\
\text { sociais acerca } & \text { da } \\
\text { inclusão } & \text { social, } \\
\text { elaboradas } & \text { por } \\
\text { pessoas } & \text { com } \\
\text { deficiência visual. }\end{array}$ & $\begin{array}{l}\text { Trata-se de uma } \\
\text { pesquisa } \\
\text { descritiva, de } \\
\text { campo, de cunho } \\
\text { quantiqualitativo } \\
\text { e apoiada em uma } \\
\text { abordagem } \\
\text { psicossociológica. }\end{array}$ & $\begin{array}{l}\text { Observou-se que as pessoas } \\
\text { com deficiência visual } \\
\text { relacionaram a inclusão } \\
\text { social com a dificuldade } \\
\text { existente para frequentar o } \\
\text { sistema regular de ensino. } \\
\text { Conforme as interlocuções } \\
\text { supracitadas, falta muito para } \\
\text { que haja um sistema } \\
\text { educacional inclusivo, como } \\
\text { é o caso da preparação dos } \\
\text { professores e do próprio } \\
\text { ambiente escolar. }\end{array}$ \\
\hline $\begin{array}{l}\text { Minorias no } \\
\text { contexto de } \\
\text { trabalho: uma } \\
\text { análise das } \\
\text { representações } \\
\text { socais de } \\
\text { estudantes } \\
\text { universitários } \\
\text { MAIA et al. } \\
\text { Brasil, 2018. }\end{array}$ & $\begin{array}{lr}\text { Identificar } & \text { como } \\
\text { estudantes } & \\
\text { universitários } & \\
\text { representam } & \text { a } \\
\text { participação } & \text { de } \\
\text { minorias sociais } & \text { no } \\
\text { contexto } & \text { de } \\
\text { trabalho. } & \end{array}$ & $\begin{array}{l}\text { Estudo com a } \\
\text { participação de } 83 \\
\text { estudantes } \\
\text { universitários de } \\
\text { diferentes cursos } \\
\text { de graduação de } \\
\text { uma universidade } \\
\text { privada da cidade } \\
\text { de Fortaleza, com } \\
\text { idades variando } \\
\text { entre } 18 \text { e } 52 \text { anos } \\
\text { que responderam } \\
\text { a um instrumento } \\
\text { de evocação, com } \\
\text { base na Técnica } \\
\text { de Associação } \\
\text { Livre re sobre } \\
\text { minorias no } \\
\text { contexto no de }\end{array}$ & $\begin{array}{l}\text { Os resultados evidenciaram } \\
\text { percepções } \\
\text { preconceitos de gebre } \\
\text { raça/cor envolvendo o } \\
\text { mercado de trabalho. Em } \\
\text { relação aos deficientes, a } \\
\text { estrutura da representação } \\
\text { apresentou o conflito } \\
\text { concernente à participação no } \\
\text { contexto de trabalho. De } \\
\text { forma específica, envolve } \\
\text { elementos como dificuldades } \\
\text { desse processo, à importância } \\
\text { de o grupo ter direitos } \\
\text { respeitados e oportunidade } \\
\text { garantidas como uma forma } \\
\text { de superação. }\end{array}$ \\
\hline
\end{tabular}




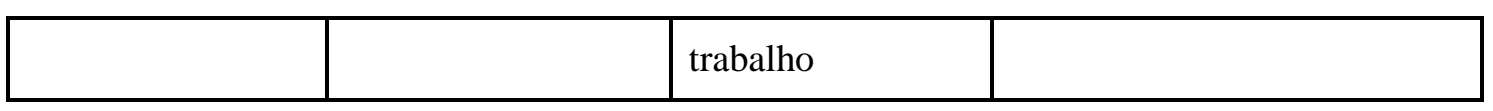

Fonte: Dados extraídos da base de dados BDENF, LILACS, Coleciona SUS e Secretaria Estadual de Saúde de São Paulo, 2020.

\section{DISCUSSÃO}

Percebe-se que existem avanços na lei, muitas com foco no processo de educação, sendo fundamental. A educação ao longo da vida não é somente direito, mas abre oportunidades para o mercado de trabalho e construção cidadã da PCD. Segundo Maia et al. (2017), analisado com entrevistas e participações de deficientes visuais e auditivos, observa-se o anseio de liberdade, esses indivíduos precisam superar para mais de barreiras físicas e básicas, a da liberdade individual de escolhas e atuação na vida. Nessa linha, seguindo o pensamento da autonomia, na sociedade atual o indivíduo está sempre buscando o seu desenvolvimento de habilidades e competências, principalmente para área profissional, na qual somos reconhecidos. O Estado atua no papel de provedor e/ou incentivador da inclusão da PCD de forma integral, sendo cultural, lazer, econômicos e afins, segundo a Lei $\mathrm{n}^{\circ}$ 13.146.2015, art. 28, inciso IX (BRASIL, 2015).

No estudo analisado sobre as representações sociais de Paulinho, Coutinho e Costa (2018), nota-se pelo olhar do próprio indivíduo, o reconhecimento formalizado obtido por meio de leis, projetos e iniciativas em diversos âmbitos da sociedade. Contudo, diante das grandes dificuldades vividas principalmente nas áreas relatadas, a saber: ambiente físico escolar inadequado, dificuldade na acessibilidade urbana, equipe educacional despreparada para lidar com a diversidade, distância entre as leis e sua aplicabilidade, desconhecimento dos direitos sociais, a dialética inclusão/exclusão.

Alega-se a discrepância do impacto que essas ações de fato têm na vida da PCD, em vista de todos os avanços e regras e inclusões que é divulgado. Considerando o ambiente escolar, por exemplo, o aluno agora tem o direito à educação e frequenta esse espaço normalmente. Porém, a presença física não necessariamente significa estar integrado e participante das atividades escolares. Diante do exposto, percebe-se a importância da representação social e mobilização das pessoas em prol da inclusão, escritos apenas não são suficientes, sendo que a própria sociedade em cada espaço é responsável por incluir e diminuir as barreiras para equidade da PCD.

Desta forma, ainda existe uma grande fragilidade na consolidação prática da inclusão. Mesmo existindo a inserção da pessoa no meio, a integração dos seres sociais 
no ambiente não acontece da forma que deveria. Sendo que, segundo Maia et al. (2018) é necessário destacar a visão diversificada das minorias, dependendo do contexto e aspectos sociais, tornando necessário observar abordagens diferentes para mudar essa mentalidade, de pouca inclusão da PCD e transformar os conceitos já enraizados, sabendo-se que será um processo lento.

Além disso, para Neri (2003), muitas vezes as políticas existentes referentes à inclusão de pessoas com deficiência, atingem as consequências e não as causas da exclusão social. Por todo esse cenário, juntamente com ações de promoção da inclusão, é crucial pensar na acessibilidade, visando a eliminação de barreiras que impedem a participação mais eficiente de um indivíduo, seja no meio social, familiar e/ou escolar. Sendo assim, é uma importante ferramenta para consolidação da inclusão, que se encontra em processo de construção.

A construção da identidade de PCDs e a inserção de corpos fora do padrão, considerado socialmente aceito e produtivo, em um contexto do capitalismo, ainda sofre influência de preconceitos estereotipados, que apresentam potencial de limitar a integração.Sendo assim, estudos que abordam esses avanços, levando em consideração as barreiras, são muito importantes para chamar atenção, em um cenário que ainda ocorrem falhas no processo de concretização da integração (PAULINO et al., 2018).

\section{CONSIDERAÇÕES FINAIS}

As observações foram feitas considerando diferentes cenários e contextos das PCD. Nos diferentes estudos, foi percebido que ainda existem comportamentos enraizados na sociedade e a exclusão acaba se fazendo presente, mesmo que em algumas situações de forma velada. Ainda, traz percepções de que a inclusão vai além da presença no ambiente, e após a evolução das legislações, é necessário pensar a inclusão para, além disso, e em como as ações propostas vão impactar no dia a dia desse cidadão, sempre tendo em vista a liberdade e poder de se desenvolver continuamente ao longo de sua trajetória. Concomitante a isso, a sociedade se mostra em um processo de desconstrução, com iniciativas para colocar a inclusão na prática, mesmo que ainda possa ser de forma lenta.

Considerando o cenário atual em que se concretiza uma inclusão não ideal, mesmo com reconhecimento da evolução da legislação, se faz necessário analisar em qual medida a inclusão é efetiva no contexto e na sociedade atual. Com isso, é notável 
as mudanças ocorridas, a legislação voltada para pessoas com deficiência apresentou grande evolução, além de estar se multiplicando pela sociedade. Porém, ainda é um tema sensível e precisa ser desenvolvido com um detalhamento sobre essa realidade, devido à sua relevância para a saúde da PCD.

Apesar de ainda existirem poucos estudos nessa temática, o que representa uma limitação, o debate é fundamental, principalmente quando se trata da socialização e integração de PCDs no contexto acadêmico e profissional, visando uma sociedade mais inclusiva, de forma concisa e integral.

\section{REFERÊNCIAS}

ALMEIDA, Leonardo Pinto de. A experiência total da leitura literária. Arquivos Brasileiros de Psicologia, Rio de Janeiro, v. 66, n. 2, p. 143-158, 2014.

ALZUGUREN, Ariana Castillo et al. Self-determination, emotions and exclusion in a blog of deaf people: a qualitative perspective. Revista Brasileira de Enfermagem, [S.L.], v. 72, n. 4, p. 1094-1101, ago. 2019.

BRASIL. Constituição (1988). Constituição da República Federativa do Brasil. Brasília, DF: Senado Federal, 1988.

BRASIL. Lei 7.853 de 24 de outubro de 1989. Dispõe sobre o apoio às pessoas portadoras de deficiência, sua integração social, sobre a Coordenadoria Nacional para Integração da Pessoa Portadora de Deficiência - Corde, institui a tutela jurisdicional de interesses coletivos ou difusos dessas pessoas, disciplina a atuação do Ministério Público, define crimes, e dá outras providências. Diário Oficial da União, Brasília, DF, 25 out. 1989. p. 19209.

BRASIL. Presidência da República. Lei 8.213 de 24 de junho de 1991. Dispõe sobre os Planos de Benefícios da Previdência Social e dá outras providências. Diário Oficial da União, Brasília, DF, 25 jul. 1991. p. 14809.

BRASIL. Lei No 13.146, de 6 de julho de 2015. Institui a Lei Brasileira de Inclusão da Pessoa com Deficiência (Estatuto da Pessoa com Deficiência). Diário Oficial da União, Brasília, DF, 07 jul. 2015. p. 2.

CORRÊA, Priscila Moreira. Acessibilidade: conceitos e formas de garantia. Revista Brasileira de Educação Especial, v. 15, n. 1, p. 171-172, abr. 2009.

COUTINHO, Maria Fernanda Cruz et al. Tratamento antirretroviral: adesão e a influência da depressão em usuários com hiv/aids atendidos na atenção primária. Saúde em Debate, v. 42, n. 116, p. 148-161, jan. 2018. 
FARAH, Marta Ferreira Santos. Análise de políticas públicas no Brasil: de uma prática não nomeada à institucionalização do. Revista de Administração Pública, [S.L.], v. 50, n. 6, p. 959-979, dez. 2016.

FIGUEIREDO, Arlete Carvalho de et al. Acessibilidade e vida universitária: pontuações sobre a educação inclusiva. In: SAMPAIO, Sônia Maria Rocha (Org.). Observatório da vida estudantil: primeiros estudos. Salvador: EDUFBA, 2011. p. 187-207.

GALVÃO, Taís Freire et al. Principais itens para relatar Revisões sistemáticas e Metaanálises: a recomendação prisma. Epidemiologia e Serviços de Saúde, v. 24, n. 2, p. 335-342, 2015.

GARBIN, Andréia de Conto. A vivência de trabalho da pessoa com deficiência e as repercussões à saúde. 2016. Tese (Doutorado em Saúde Ambiental) - Faculdade de Saúde Pública, Universidade de São Paulo, São Paulo, 2016.

KASTRUP, Virgínia et al. Inclusão e Acessibilidade para Pessoas com Deficiência. Psicologia: Ciência e Profissão, Brasília, v. 38, n. 3, p. 551-553, 2018.

KRAEMER, Graciele Marjana; THOMA, Adriana da Silva. A Modulação das Condutas das Pessoas com Deficiência no Contexto Educacional Brasileiro de Inclusão. Revista Brasileira de Educação Especial, v. 25, n. 3, p. 421-434, 2019.

MAIA, Luciana Maria et al. Minorias no contexto de trabalho: uma análise das representações socais de estudantes universitários. Psicologia e Saber Social, v. 6, n. 2, p. 223-242, 2018.

MANCINI, Marisa Cotta; SAMPAIO, Rosana Ferreira. Quando o objeto de estudo é a literatura: estudos de revisão. Revista Brasileira de Fisioterapia, v. 10, n. 4, p. 1-2, 2006.

MARIANO, Ari Melo; SANTOS, Maíra Rocha. Revisão da Literatura: apresentação de uma abordagem integradora. In: AEDEM INTERNATIONAL CONFERENCE, Não use números Romanos ou letras, use somente números Arábicos, 2017, Reggio di Calabria (Itália). Anais [...]. Itália: AEDEM, 2017. p. 427-443.

MILANI, Fernanda Gimenez; STAREPRAVO, Fernando Augusto. Um olhar multidisciplinar sobre a inclusão social: resenha do livro políticas públicas de esporte/ lazer e in(ex)clusão de pessoas com deficiência. Brazilian Journal of Science and Movement, v. 25, n. 3, p. 187-191, 2017.

MOYSES, Samuel Jorge et al. Avaliando o processo de construção de políticas públicas de promoção de saúde: a experiência de Curitiba. Ciência \& Saúde Coletiva, Rio de Janeiro, v. 9, n. 3, p. 627-641, 2004.

NERI, Marcelo et al. Retratos da deficiência no Brasil. Rio de Janeiro: Fundação Banco do Brasil, FGV/CPS, 2003. 
PAULINO, Ana Cristina de Oliveira Borba et al. Apreendendo a inclusão social sob o olhar das representações sociais. Estudos e Pesquisas em Psicologia, v. 18, n. 3, p. 773-792, 2019.

REIS, Ana Cristina et al. A mortalidade por aids no Brasil: um estudo exploratório de sua evolução temporal. Epidemiologia e Serviços de Saúde, v. 16, n. 3, p. 195-205, 2007.

SOUZA, Celina. Políticas públicas: uma revisão da literatura. Sociologias, n. 16, p. 20 45, 2006.

VILLARINHO, Mariana Vieira et al. Políticas públicas de saúde face à epidemia da AIDS e a assistência às pessoas com a doença. Revista Brasileira de Enfermagem, v. 66, n. 2, p. 271-277, 2013.

WANDERER, Aline; PEDROZA, Regina Lúcia Sucupira. A violência como tema transversal aos estudos sobre a deficiência: interconexões necessárias. Estudos e Pesquisas em Psicologia, Rio de Janeiro, v. 15, n. 1, p. 178-195, 2015.

WEIBLE, Christopher M.; CARTER, David P. Advancing Policy Process Research at Its Overlap with Public Management Scholarship and Nonprofit and Voluntary Action Studies. Policy Studies Journal, v. 45, n. 1, p. 22-49, 2016.

\section{Recebido em: 15/10/2021}

Aprovado em: 18/11/2021

Publicado em: 20/11/2021 